\title{
LA TEORÍA DE LA RECEPCIÓN: EL PROBLEMA DE SUBJETIVIDAD
}

\section{UBICACIÓN DEL TEMA}

El objeto artístico $-\mathrm{y}$, del mismo modo, cualquier otro productocrea un público sensible al arte y capaz de goce estético. La producción produce, por ello, no sólo un objeto para el sujeto, sino también un sujeto para el objeto.

Esta relación entre el sujeto y el objeto artístico tal como la formuló Karl Marx en su Introducción a la Crítica de la economia politica, ${ }^{1}$ nos puede servir como punto de partida para entrar al tema. La definición anticipa el enfoquc de una corriente relativamente nueva de la poética que suele llamarse la teoría de la recepción. Plantea el problema de la relación comunicativa entre el sujeto y el objeto, concretamente entre cl público y la obra literaria, e investiga la manera de cómo los lectores de diferentes clases, países, siglos han acogido, leído, interrogado, criticado las obras literarias a través de la historia. La teoría de la recepción estudia cse diálogo, ese juego entre obra y receptor y trata de rescribir la historia desde el punto de vista de los lectores.

El replanteamiento de la estética como estética de recepción en lugar de la tradicional estética de producción y de presentación ha despertado mucho interés en el mundo de las ciencias literarias: este hecho no sólo se pone de manifiesto; a través de las múltiples publicaciones de los últimos años, ${ }^{2}$

${ }^{1}$ Marx y Engels, Escritos sobre arte. Buenos Aires (Futura), 1976, p. 53.

${ }^{2}$ Se encuentran amplias bibliografías en las siguientes publicaciones: Gunter Grimm (ed.), Literatur und Leser, Theorien und Modelle zuir Rezeption literarischer Werke. Stuttgart (Reclam) 1975; Gunter Grimm, Rezeptionsegeschichte, Grundlegung einer Theorie. Mit Analysen und Bibliographie. Munich (Fink) 1977. 
sino también por otros medios de nucstro ambiente que señalan oportunamente la actualidad de una corriente: Así, por ejemplo, la revista Poétique dedicó un número a la "Théorie de la réception en Allemagne", ${ }^{3}$ y en el Congreso de la Asociación Internacional de Litcratura Comparada que tuvo lugar en Innsbruck, la sccción I sesionó bajo el tema de "Communication littéraire et réception".

No voy a presentar a ustedes un panorama del estado actual de las investigaciones acerca de todos los problemas de la recepción. No sólo porque sería imposible en una conferencia, sino también porque me inquieta un problema específico de la recepción: cl de la subjetividad del receptor. Y eso, para decirlo desde un principio, con miras hacia un público que se inicia en la teoría literaria y en cl análisis científico del texto literario: los estudiantes de Letras. Mi enfoque será entonces didáctico, porque pienso que la reflexión teórica de los universitarios sobre temas poéticos debería, de alguna manera, tener repercusiones en la enseñanza. Y precisamente, dentro de las diferentes tendencias de la teoría de la recepción hay una que está espccialmente orientada hacia problemas de la didáctica de la literatura. La teoría de la recepción ha estimulado mucho la discusión acerca de los métodos y contenidos de la enseñanza actual de la literatura, realzando el papel que tienen y han tenido en el pasado los lectores para la historia literaria.

El interćs por el lector no es nuevo. Basta recordar algunos de los "clásicos" de la sociología de la literatura, como Levin Schücking con su lúcido estudio sobre El gusto literario (1931), \& el tantas veces citado ensayo de Jean-Paul Sartre, Qu'est-ce que la littérature? (1948), "5 la Historia social de la literatura y del arte de Arnold Hauser (1953), ${ }^{6}$ o las obras La littérature et le lecteur de Arthur Nisin (1959). ${ }^{7}$ y Socio-

\section{Poétique, núm. 39,1979}

4 Levin E. Schücking, Die Soziologie der literarischen Geschmacksbildung. Ed. en español: El gusto literario. México (Fondo de Cultura Económica) 1950.

5 Jean-Paul Sartre, Qu'est-ce que la littérature. París, 1948.

6 Arnold Hauser, Sozialgeschichte der Kunst und Literatur. Munich, 1958.

7 Arthur Nisin, La littérature et le lecteur. París, 1959. 
logie de la littérature de Robert Escarpit (1958) que apareció en alemán bajo el título significativo de El libro y el lector. ${ }^{8}$ Además se podrian citar los trabajos de Roland Barthes, Erich Auerbàch, Félix Vodicka y los de muchos otros más que reflexionaron acerca de la relación comunicativa entre la obra literaria y el público, una relación dialéctica que ya conocieron los antiguos: "Pro captu lectoris habent sua fata libelli" -Según los entiende cl lector, tienen su destino los libros (Terentianus Maurus, siglo III. ${ }^{9} \mathrm{Y}$ el escritor alemán Georg Christoph Lichtenberg (1742-1799) escribió: "Es muy bueno leer una y otra vez los libros que otra gente ya ha leído cien veces, porque si bien el objeto queda el mismo, sí cambia cl sujcto (que los lec)." 10

La pregunta acerca de la participación del lector en el acto de concretización de la obra literaria se plantea con intensidad sobre todo a partir de los años 60 , y no sólo en Alemania. El interés creciente en los últimos 15 años por la interrelación autor-obra-lector, sólo es un indicio de la importancia que atribuyen muchas disciplinas a los procesos comunicativos. El enfoque de la "Escuela de Constanza" -nombre de la Universiclad donde se han concentrado gran número de investigadores intercsado en cuestiones de recepción literaria--, estaba al principio orientado hacia una teoría de la recepción basada en una ciencia del texto. Hoy se orienta cada vez más hacia una teoría de la comunicación y participa con esto en un proceso sintomático en cl que participan también otras ciencias. Desde finales de los años sesentá, la lingüística, la semiótica, la sociología, la antropología, la filosofía se han ido alcjando poco a poco del estructuralismo cicntífico. El distanciamiento fue acompañado por la crítica a este método (o paradigma, como dirían los teóricos de la

8 Robert Escarpit, Sociologie de la littérature. París, 1958. Ed. en español: Sociología de la literatura. Barcclona (Oikos-tau) 1971. p. 401 .

9 Cita tomada de: Büchmann, Geflügelte Worte. Stuttgart (Reclam) 1956,

10 Cita tomada de: Gunter Grimm, 1977, p. 4 (La traducción cs mía). 
recepción, siguiendo la terminología de Thomas $\mathrm{S}$. Kuhn); ${ }^{11}$ se criticaban los sistemas lingüísticos ccrrados formalizados, sin referencia y sin sujctos que participan necesariamente en la comunicación. Al mismo tiempo que se rehabilita en las. ciencias literarias al lector, al oyente, al espectador --en una palabra al receptor- la lingüística del texto se abre hacia una pragmática de los actos verbalcs y hácia el análisis de conversación; $y$ encontramos tendencias semejantes en otras cicncias. 12

Para darnos una idea de cómo los "recepcionistas" ven un estrecho enlace entre la evolución de las teorías lingüísticas y literarias, dejo la palabra a uno de ellos, Harald Weinrich, quien dice:

La teoría sintáctica aquí presupone una concepción no monológica (iesa triste figura del native speaker solitario! sino dialógica del lenguaje; cl modelo fundamental de la comunicación debe ser el del intercambio entre un locutor (o autor) y un alocutario (o lector). En esta comunicación dialógica, que hay que presentar si es posible en forma de "comunicación frente a frente", el signo lingüístico es un segmento textual para el cual el cmisor induce al receptor a comportarse de cierta mancra. Según csta concepción, el signo lingüístico es un acto de instrucción en situación comunicativa, y la lingüística que corresponde a esa teoria la podemos llamar pragmática o más exactamente instruccional. 13

Sin querer profundizar más en estas reflexiones, vuelvo a algunos aspectos de la teoría de la recepción. E1 mismo Harald Weinrich en 1967 postuló:

11 Thomas S. Kuhn, Die Struktur wissenchaftlicher Revolutionen. Frankfurt (Suhrkamp) 1967. Sobre este tema: Hans Robert Jauss, "Paradigmawcchsel.in der Literaturwissenchaft", en: Wiktor Zmegac (ed.), Methoden der deutschen Literaturwissenschaft, Eine Dohumentation. Frankfurt (Athenäum), 1974, pp. 274-290. Además: Hans Ulrich Gumbrecht, "Konsequenzen der Rezeptionsästhetik oder Literaturwissenschaft ais Kommunikationssoziologie", en Poetica, Zeitschrift fiir Sprach- und Literaturwissenschaft. Amsterdam, 1975, pp. 388-413.

12 Cf. Theorie der Literatur und der Kommunikation. Postraduierten-Programm der Universität Konstanz. Wintersemester 1975/80. 339 .

13 Harald Weinrich, "Les temps et les personnes". En: Poétique, 1979, o. 
El lector tambićn merece ser tenido en cuenta. Por él hay litertura, y los autores tienen sus motivos para dirigirse a él en sus prólogos, llamándolo "amable" o "propicio" 14

Las historias literarias normalmente olvidan al lector; se. ocupan de las "obras" y de los autores, de sus conflictos, sus amores, sus sufrimientos, su muerte. Sin embargo, la experiencia y la situación histórico-social de los lectores en general no coinciden con la perspectiva de los autores. Por eso no solamente es necesario reconstruir el sociograma de los lectores de una obra literaria mediante métodos empíricos --de lo cual se ha ocupado mucho la sociología de la literatura-, sino también hay que describir "el papel del lector que subyace en la obra misma. Toda obra literaria conlleva la imagen de su lector. Podemos afirmar que el lector es un personaje de la obra" 15 Volveré a este problema.

Junto con otros trabajos fundamentales, el de Weinrich ha estimulado la discusión acerca de la enseñanza de la literatura en las universidades alemanas. Sobre todo fue el estudio de 1967 de Hans Robert Jauss el que marcó un giro en los estu. dios literarios. Se publicó en un momento de malestar general provocado por la tradicional forma de cnseñar la literatura en las universidades y la enseñanza media superior. Desde entonces, los estímulos que ha dado el enfoque "recepcionista" han resultado fructíferos para la didáctica de la literatura. De hecho, los estudios acerca de la recepción y el efecto de las obras literarias -en el sentido más amplio de lá palabraofrecen la oportunidad de combinar investigación y enseñanza. Porque estudiar en conjunto los procesos de lectura, analizar las pautas estéticas de diferentes épocas y su interdependencia con las respectivas situaciones socioculturales, hacer estudios empíricos sobre la subjetividad y objetividad de la crítica literaria, investigar acerca del comportamiento de grupos de lectores definidos, del papel de la propaganda y de las editoriales: todo esto y mucho más puede estirnular

14 Harald Weinrich, "Para una historia literaria del lector", en H. U. Gumbrecht, et al., La actual ciencia literaria alemanc. Salamanca (Anaya) 1971, p. 116.

15 Ibid., p. 124. 
el interés de los educandos en la lectura y la literatura. ${ }^{16}$

Tengo la impresión de que también en América Latina hay un interés creciente por el papel de los lectores en la recepción de la literatura. Se nota una toma de conciencia acerca de la actualidad del problema. Pero qứizás se disponga todavía de muy pocos datos acerca de las costumbres, de los intereses y necesidades de lectura de las diferentes capas sociales, de las edades, de los niveles educativos. Se oye mucho que la juventud lee poco, sin contar a los que nunca aprendicron a leer. Pcro "sin lectores, dicen las buenas lenguas, no hay litcratura". 17 Ariel Dorfman discute ese problema desde cl punto de los escritorés latinoamericanos, y llega a la conclusión de que "de nuestros lectores, la verdad, tenemos poca información".

Sin referirse a una corriente o cscuela de la teoría literaria, Dorfman insiste en el papel creador del lector sin cl cual no es posible una democratización de la socieddad: Con este fin, los escritores deben ganarse a los lectores, y dice:

me parece, como lo sugiere la mejor literatura hispanoamericana de los últimos decenios, que la redención del lector como ente estético depende de la estrategia literaria de las tácticas de construcción de la obra. Nucstra literatura organiza su asalto persuasivo con el objeto de inducir al receptor ${ }^{2}$ una mayor participación, desgarrándolo para que salya de su pasividad y abulia, invitándolo a recorrer juntos la creación de un continente, de un Ienguaje, de una ficción, todavia inacabados (p. 11).

Y todavía van más lejos las postulaciones de Dorfman cuando ve en el lector algo como un guía del futuro literario: propone:

confiar en el lector, permitirle que sea él quien vaya decidiendo los vaivenes y oricntaciones, las obsesiones $y$ paradojas, que la

16 Hans Robert Jauss, "La historia literaria como desafío a la ciencia litcraria", cn: H. U. Gumbrecht, et al., 1971. Sobre aspectos didácticos: Eberhard Lämmert, "Rezeptions- und Wirkungsgeschichte der Litcratur als Lchregenstand", en: Neue Ansichten einer Künftigen Germanistik, ed. por Jürgen Kolbc, Munich (Hanser) 1973, pp. 160-173.

17 Ariel Dorfman, "Problemas para la liberación del lector en América Latina". Fn: Revista de la Universidad de México, julio, 1979, p. 10. 
obra incita. Esto sólo es concebible si se respeta al lector profundamente, si se lo trata como si fuera un ciudadano del futuro ( $p$. 13).

También Julio Cortázar, par'd citar solamente a uno de los más conocidos escritores latinoamericanos, destaca la importancia de los lectores para la creación literaria. En una conferencia con el título El lector y el escritor, dictada en 1978 en Estocolmo, hablaba de la interacción entre lector y escritor y comparaba la posición más bien pasiva del lector del pasado con la más activa del de hoy en día:

El lector de antaño esperaba los libros que la predilección o el azar iban trayendo a sus manos; el lector de hoy, de muchas maneras directas o indirectas, los reclama. 18

Ahora bien, esta digresión nos permite por un lado, subrayar la importancia del lector de hoy en su relación pragnática con el autor y las obras.

Por otro lado, nos hace ver más claramente el enfoque de la cstética de la recepción, que por cierto también se interesa por el lector, pero no primordialmente en su relación con el autor, sino con la obra. Y sc interesa específicamente desde un punto de vista de la historia literaria. La interrelación entre el autor y su público así como también la correspondencia funcional de la literatura con la sociedad (la literatura es la reproducción de una realidad sociocultural preexistente) son temas de investigación de la sociología literaria tradicional. Sin embargo, tambićn la tcoría o estćtica de la reccpción subraya el carácter histórico-sócial de la rclación obra-público. Hans Robert Jauss escribe:

La historicidad de la literatura no depende de la coherencia de unos "hechos literarios" que puede verse retrospectivamente, sino del contacto vivo de la obra literaria con sus lectores. La relación establecida por el diálogo es el presupuesto de la historiografía de la literatura. El historiador tiene que adoptar continuamente la función del lector para ser capaz de comprender y

18 Julio Cortázar, "El lector y el escritor", en: Arte, sociedad, ideología, núm. 5, 1978, p. 98 . 
clasificar una obra, es decir: fundamentar su propio juicio porque conoce su lugar dentro de la sucesión histórica de los lectores. 19

Sin ahora entrar en la discusión sobre si "el lector" de Jauss en un "superlector", un literario culto, superprivilegiado que lo sabe todo (cia lo mejor un catedrático universitario?), para Jauss

la teoría recepcional permite comprender el sentido y la forma de la obra literaria por la variedad histórica de sus interpretaciones. ${ }^{20}$

La historicidad de la literatura y especialmente de sus obras maestras, se basa, según Jauss, en la experiencia de sus lectores a través de los tiempos. Las experiencias sirven de intermediario entre pasado y presente. Cada interpretación tiene que tomar en cuenta la constante interacción entre obra, público $y$ autor, y las diferentes concretizaciones que dependen del horizonte de expectativas de cada lector y del público en general, siempre en su contexto histórico, cultural y social, y que orienta la comprensión. Jauss entiende eI horizonte de expectativas del público

como aquella instancia ante la cual se rcaliza la articulación de cucstiones de la práctica de la vida en el arte, asi como también cl cambio de la expcriencia estética en una preformativa comprensión del mundo. 21

La definición o reconstrucción del horizonte de expectativas de un público es necesario para explicar las interpretaciones parciales o subjetivas que se deben muchas veces a la distancia estética entre el lector y una obra (nueva). Por eso,

la cuestión acerca de la subjetividad de la interpretación y del gusto de diversos lectores, o sectores de lectores, sólo pucde formularse de una mancra lógica si antes se ha aclarado cuál es eI

19 H. R. Jauss, "La historia literaria como desafío a la ciencia literaria", en: H. U. Gumbrecht, et al., 1971, p. 7 I.

20 Jbid., p. 91.

21 Hans Robert Jauss, La literatura como provocación. Barcelona (Península), 1976, p. 10. 
horizonte transubjetivo del entendimiento que condiciona el efecto del texto). 22

El éxito o la recepción positiva de una obra literaria podría definirse como resultado de la congruencia entre el horizonte de expectativas de un grupo social y la intención de la obra. Cuando la distancia estética es mínima, podemíos esperar un éxito espontáneo (hoy en día muchas veces prefabricado y manipulado por las editoriales y los medios de información). Cuando la distancia estética es grande, el público puede reaccionar de manera reservada y con esta actitud retrasar o hasta impedir el éxito. Sólo un cambio de horizonte, debido a nuevas experiencias estéticas y/o sociales etc., del público y de la crítica traerá consigo la recepción respectiva, sea del lector individual, sea de la comunidad sociocultural. ${ }^{23}$

\section{EJEMPLO DE APLICACIÓN DE LA TEORÍA DE LA RECEPCIÓN}

Para ilustrar cómo pueden. ser aplicados los principios de la teoría de la recepción, voy a presentar en esta segunda parte de mi trabajo los resultados de un experimento acerca de la recepción de un texto literario. Al mismo tiempo entraré en el problema de la subjetividad de la recepción.

A estudiantes de diferentes carreras de la UNAM, la mayoría sin embargo de la. Facultad de Filosofía y Letras, se les presentó el siguiente texto:

Fil recencuentro

Un conocido al que el señor K. no había visto desde hacía ticmpo lo saludó con estas palabras: - iCarambal, señor Keuner, no ha cambiado usted nada! - iOh! - exclamó éste palideciendo. 24

Sin otra explicación se les pidió a los estudiantes que comentaran por escrito, con la mayor libertad de asociaciones,

22 Ibid., p. 172 .

23 Robert Escarpit, Escritura y comunicación. Madrid (Castalia), 1975, p. 89; H. Heuermann, P. Hühn, B. Röttger, "Modell einer rezeptionsanalytschen Literaturdidaktik", en: HL Heuermann, et al., (ed.), Literarische Rezeption. Paderborn (Schöningh), 1975, p. 94.

24 Bertolt Brecht, Historias del señor Ketner. Barcelona (Barral), 1974, p. 26. 
el texto. No se Ies dijo que se trataba de un texto literario, tomado de las Historias del señor Keuner de Bertolt Brecht, y ninguno de los alumnos - tampoco los de Letras Alemanas, asoció a Brecht, a pesar del nombre Keuner. Éste, por cierto, no está en el original de la presente historia; en cl texto alemán sólo se dice "el señor K.".

El hecho de no mencionar que se trataba de un texto de Brecht se hizo con la finalidad de que Ios estudiantes no tomaran una posición "literaria" frente al texto, que puede ser tanto de respeto y seriedad como también de recha\%o. Porque sabemos que un gran número de alumnos llegan a la universidad con un trauma referente a la enseñanza de la literatura como Ia conocieron en la preparatoria. $\mathrm{Su}$ "horizonte de expectativas" está deformado, y se cierran frente a un texto cuando se les dice que es "alta literatura". Por experiencia dolorosa, es decir, malas calificaciones, saben que nunca o sólo pocas veces han logrado la "buena lectura" la lcctura "correcta" del texto literario que solamente conocía su profesor o el manual de historia literaria.

Aunque, afortunadamente, una parte del estudiantado --y obviamente una bucna parte del de Letras- lee con gusto y aprecia la literatura (en el sentido tradicional), parece que justamente el aspecto importantísimo de la recepción queda muchas veces excluido del estudio de la literatura, también en las carreras de Letras, dentro de la Facultad de Filosofía y Letras. Cristina Barros Valero, en su estudio sobre la carrera de Lengua y Literaturas Hispánicas, 25 concluyó en el párrafo sobre El aspecto metodológico de la cnseñanza de la literatura lo siguiente:

Al analizar la parte metodológica, fundamental en la enscñan\%a, el resultado es que la mayoría de los profesores consideran necesario utilizar métodos que se basen en cl análisis de la obra literaria. En los comentarios se hace también hincapié en lat neccsidad de que los cursos sean más activos, que los alumnos participen y que las materias sean más formativas que informativas.

En este mismo sentido los alumnos consideran que los defectos metodológicos son: que no se analizan directamente los textos

25 Cristina Barros Valero, La carrera de lengua y literaturas hispánicas, Una contribución a su análisis. México (UNAM), 1978. 
literarios, que muchas veces se presentan las idcas del autor, pero se olvida el aspecto estilístico, $y$ que se pone demasiado enfásis en la historia de la literatura; opinan además que no se estimula cl interés y la creatividad de los alumnos.

Los alumnos comentan acerca de los aspectos metodológicos: "se da demasiado énfasis a la memorización mecánica y" a la repetición sin comprensión por parte del alumno. En otras matcrias se adopta una actitud rígida y dogmática por parte del macstro que intimida al alumno, no hay diálogo ni intercambio de ideas $y$, mucho menos, crítica o aportación personal ni de una ni de otra (p. 90).

Me parece que ante tales obstáculos que impiden la recepción espontánea de un texto literario, se hace necesaria también aquí una discusión a fondo de la didáctica de la literatura. El enfoque empírico de la teoría de la recepción podría ser tomado en cuenta para por lo menos romper esa actitud de rechazo, llena de prejuicios, frente a Ia enseñanza de la literatura que parece prevalecer en parte de la sociedad. ¿Cuál fue entonces la reacción ante $E l$ reencuentro de Brecht?

Entre los estudiantes-receptores que leycron y comentaron el texto podemos grosso modo distinguir tres grupos: uno que tiende a "interpretar" el texto, es decir a tratar de entender lo dicho y de llenar los "vacíos" $\rightarrow$ o lo no dicho- para así constituir un texto nuevo. El resultado suele ser una proyección de su propia personalidad. El segundo grupo reflexiona más bien sobre la forma del texto pero no lo reescribe, sino usa el metalenguaje lingüístico o poético para reflexionar sobre la identidad de los dos personajes del texto, sobre estrategias comunicativas o sobre si el texto es un texto o no. Evidentemente, en el último grupo se encuentran sobre todo estudiantes de filosofía, lingüística y letras que -como era de esperarse - manifestaron claramente su "deformación profesional". En tercer lugar hubo estudiantes que combinaron los dos procedimientos: ofrecieron una interpretación subjetiva-psicologista, y además hicieron algunos comentarios teóricos.

Un ejemplo para cada grupo:

Grupo 1 El comentario no fue un halago como pretendía el primer hablante, fue desilusionante. Uno espera 
cambiar con el tiempo, no permanecer igual. (Letras Hispánicas.)

Grupo 2 En esta secuencia de oraciones encontramos diversos tipos de información: se nos presenta a un personaje que es identificado por medio de un nombre propio; existe otro personaje que no tiene nombre y al que sólo se le identifica por su relación con el otro personaje. Por otra parte, el saludo corresponde al tipo de saludos formales entre personas cuyo trato no es muy íntimo, etc. (Lingüística).

Grupo $3 \mathrm{Me}$ parece que estas líneas forman parte de un texto (por ejemplo de una novela, un cuento o incluso de un chiste de revista). (Entiendo por "texto" un escrito acabado en el que cada una de sus partes se relaciona con las demás.) Aparecen un narrador y dos personajes. Sólo sabemos el nombre de uno de los últimos: Keuner (no me resulta explicable el por qué aparece el nombre de este personaje primero con una inicial y después completo). Tampoco parece explicable el por qué palidece, incluso es absurdo puesto que el comentario que le hizo su conocido resulta un halago, sin embargo podría explicarse si pensamos que tal vez en el pasado hubo algún problema que el conocido olvidó y el Sr. Keuner recuerda al volver a ver a su amigo. El hecho de que el párrafo (por llamarlo de alguna manera) tenga título me hace pensar más en que se trate de un chiste. (Lingüística.)

En estas tres recepciones del texto tenemos ya muchos elementos que se pueden incluir en un cuadro ya más sistemático de temas y proyecciones que surgieron a través de la lectura del texto.

1. Comentarios sobre el uso de giros, fórmulas, openers, en una situación comunicativa.

a) La fórmula "no ha usted cambiado nada" es un halago, positivo. 
b) La fórmula "no ha usted cambiado nada" es una forma convencional.

c) El opener es inadecuado, porque así no se empieza una conversación después de mucho tiempo transcurrido.

2. Lua reacción del señor $\mathrm{K}$.

a) EI "Oh" es inadecuado, no permite que continúe la comunicación: "La respuesta iOh! de asombro corta en seco la pregunta del conocido." (Lingüística.)

b) EI "Oh" significa que el Sr. K. se ve "sorprendido" por el encuentro inesperado.

c) El "Oh" significa que sí ha cambiado, pero el otro no se da cuenta; "el 'Oh' toma un significado de desaliento para Herrn K." (Ingeniería).

d) El "Oh" significa que está decepcionado porque el conocido no se ha dado cuenta de cambios externos: de "una operación de cirugía plástica". (Secretaria.)

e) Se trata de un malentendido: El Sr.K. no es la person: por la cual lo toma el conocido. ("Más posiblemente, el Sr. K. que conoce cl individuo no sea el Sr. Keuner, sino alguien parecido o semejante y entonces lo ha confundido con el sujeto que conoce, y al saludarlo, el individuo saludado se sorprende y palidece, reaccionando así ante la sorpresa de alguien al que él no conoce.") (Filosofía)

f) El Sr.K. exclama iOh! porque no quiere que alguien lo reconozca, por un pasado criminal o por lo menos problemático. ("El que palidezca el Sr. K. quiere decir un miedo a mostrarse, $y$ esto no sucede por deber dinero -en ese caso se hubiera tratado de csconder, o mostrar resignación, pero no hubiera palidecido-, sino por problemas íntimos de índole psicológica. . .") (Filosofía).

3) El texto como punto de partida para llevar a un fin la situación comunicativa que fue considerada incompleta.

Dos estudiantes - seguramente futuros o actuales escritores se inspiraron en la forma abierta del texto de Brecht y lo "terminaron", incluyendo en la obra temas ya conocidos.

4) Discusión sobre la pregunta de si se trata de un verdadero texto (en el sentido lingüístico no muy bien definido). 
5) Discusión de la pregunta de si el señor K. es el señor Keuner.

6) Intento de situar el texto dentro de la historia literaria, asociándolo con obras de otros autores: "Esto me recuerda. . ." (fueron mencionados Dostoievski, Hesse, Oscar Wilde -concretamente El retrato de Dorian Gray-, Kafka).

Los resultados de esta pequeña encuesta sobre las formas de recepción de un texto literario en un grupo social relativamente homogéneo (estudiantado de la UNAM) coincide en grandes rasgos con una encuesta comparable que Heinz Hillmann llcvó a cabo en Alemania entre un grupo de aproximadamente 300 estudiantes dc escuelas secundarias, preparatorias $\mathrm{y}$ de nivel profesional. ${ }^{26}$ Hillmann pudo agrupar las respuestas en tres grupos temáticos:

A: Constatación de giros convencionales en una conversación y posiciones críticas o afirmativas al respecto.

B: Constatación de los tipos de cambio -real o deseado del Sr. K. (incluyendo consideraciones sobre cambios exteriores, belleza, color, salud, peso), e interiores.

C: Pasado anormal o criminal; cambio hacia lo positivo o continuación disimulada del comportamiento original.

Mientras que A y B estaban distribuidos de manera comparable entre alumnos de secundaria y preparatoria, aunque con difcrentes acentos, el $\mathrm{C}$ (esquema criminal) fue escogido dos veces más por los alumnos de secundaria que por los de preparatoria. Salta a la vista que las interpretaciones subjetivas y espontáneas eran mucho más frecuentes entre los alumnos europeos que entre el estudiantado de la UNAM, en donde encontré una marcada tendencia hacia el comentario teórico. Sobre todo, Hillmann no menciona comentarios ligados con tcorías lingüísticas o literarias, aunque sí hubo intentos de situar el texto dentro de la historia literaria.

Un fenómeno que también sería interesante investigar es el "horizonte de expectativas" extraestético de los estudiantes: según cl ambicnte, la materia de la clase en que se les pidió que comentaran el texto, fue modificada su recepción.

26 Heinz Hillmann, "Rezeption - empirisch", en: H. Heuermann, et al. (ed.), Literarische Rezeption. Padcrborn, 1975, pp. 113-130. 
Dentro de una clase de literatura: comentarios teóricos; dentro de un contexto lingüístico: análisis lingüístico. ¿Cómo hubieran reaccionado estos estudiantes leyendo el texto solos?

Lo que no aparece en la cncuesta europea es la discusión sobre la idcntidad del Sr. K. (ं es el Sr. Keuner o no lo es?). Pero aquí no hay que buscar un problema de identidad del estudiante mexicano, sino simplemente se trata de un problema de traducción.

No sin razón, uno de los temas del Congreso de Literatura Comparada de Innsbruck fue "La traducción literaria como problema de recepción". Tanto la teoría de la recepción como la sociología de la literatura están enfocadas, entre otras cosas, hacia cuestiones de traducción, como lo subraya Robert Escarpit en su Sociología de la literatura, cuando dice que "el estudio de la traducción está estrechamente vinculado a los aspectos sociológicos de la historia literaria". 27

En el pequeño texto de Brecht, el traductor ha hecho varios cambios que necesariamente deben originar una recepción diferente entre el público de lengua alemana y el de lengua castellana. Así el "conocido" del señor K. era en el original sólo "un hombre", lo que cambia la relación entre los dos personajes y explica el por qué se dirige al Sr. K. con un iCaramba! confidencial que no se encuentra en el texto alemán. Sobre todo, en el texto español el Sr. K. aparece la primera vez como "señor K." y la segunda como "Sr.Keuner", lo que originó en algunos estudiantes esa inseguridad sobre su identidad. Además no es muy común y aquí absolutamente innecesario introducir, primero, la proforma de manera catafórica y sólo después la forma completa.

Partiendo de las siguicntes preguntas podré llegar a la evaluación de los resultados:

1. ¿Es legítima esta manera de trabajar con un texto literario para obtener información sobre su recepción?

2. ¿No conduce un tal procedimiento a la afirmación incondicional del subjetivismo en la recepción de un texto?

27 Robert Escarpit, Sociologia. ., op. cit., p. 100. 
3. ¿En qué medida nos puede ayudar un método tal para la didáctica de la literatura?

El mismo Hans Robert Jauss cvaluó el experimento de Hillmann. 28 Voy a tomar en cuenta la crítica de Jauss -autoridad reconocida en la especialidad-para evaluar mi propia encuesta comparable a la de Hillmann.

1. Según Jauss, la situación recepcional es artificial porque se sacó el texto de un contcxto literario y con esto se prescinde de una condición estética fundamental. Tengo la misma opinión, porque de hecho la historia es sólo una de las 87 historias del Sr. Keuner, y a través de la lectura de todas se obtiene una imagen mucho más completa del carácter del Sr. $K$. , una imagen que ya no permite muchas de las interpretaciones subjetivas de los lectores. Este reconocimiento podría ser el punto de partida para concientizar al estudiante de literatura respecto al problema de la sclección de textos, y respecto a las consecucncias de recepción de fragmentos de tcxtos. Lcer fragmentos, conocer la literatura sólo a través de antologías cuyos criterios de selección se desconocen, implica estar sujeto a una reccpción manipulada. Tales reflexiones Ilevan necesariamentc al problema del canon, del corpus de la enseñanza literaria. Los planes de estudio, las listas de lectura, son elaboradas muchas veces sin tomar en cuenta, o por lo menos en un grado no suficiente, al estudiantado. De ahí la actitud refractaria de grandes mayorías de estudiantes, sobre todo del nivel medio superior, frente a la clase de literatura. Tanto más cuanto ciertos profesores -así se me informó- no hacen leer ninguna obra original, sino se limitan a obligar a los estudiantes a aprender de memoria títulos y las fechas biográficas de los autorcs. Razón suficiente para rechazar tal "enseñanza literaria" y volver a la lectura de historietas. Pero cambiar justamente este horizonte de expectativas sería uno de los abjetivos de xma enseñanza emancipatoria de la literatura: "Es una enscñanza que debería cxcluir, pues, toda idea de un corpus histórico y estético de obras

28 Hans Robert Jauss, "Der Leser als Instanz einer neuen Geschichte der Literatur", en: Poetica, 1975, pp. 325-344. 
que un consenso elitista reconoce como literatura, y huir del aburrimiento de las admiraciones obligatorias." 29

2. Como segundo punto en la evaluación de la recepción empírica de la historia del Sr. Kcuncr, se puede alegar que esta manera de trabajar con el texto no capta lo esencialmente literario del mensaje sino que nos proporciona soldmente información sobre la psicología, la ideología, la actitud subjetivista de los receptores. Lo que a primera vista parece sólo una estadística casual con un gran número de opiniones heterogéneas que reflejan recepciones subjetivas, en realidad puede arrojar datos útiles sobre la manera de leer de un grupo social definido. Por lo menos resulta estimulante para los estudiantes cuando se discute con ellos los resultados. Lo que más se deja explotar didácticamente es la aceptación de opiniones divergentes; el hecho de aceptar opiniones opuestas y la experiencia de que los textos no son sistemas cerrados, puede llevar a un cambio de actitud frente a la literatura. No se trata de buscar la "lectura correcta" como única admitida, el "sentido" que cl autor ha escondido en el texto. O, como dijo Roland Barthes, no hay que tomar al autor como dueño eterno de su obra, y nosotros los lectores sólo como usufructuarios. Esta economía implica naturalmente una reivindicación de autoridad: el autor -así se piensa cuando se ignora la perspectiva del receptor- tienc derechos frente al lector; le impone un sentido definido de la obra; y este sentido, naturalmente, es el bueno, cl verdadero. Y esto es un contrasentido: se intenta captar lo que quería decir el autor pero de ninguna manera lo que percibe el lector. 30 Pero claro: la averiguación de lecturas subjetivas no puede ser el objetivo final del trabajo. La aceptación de recepciones subjetivas es sólo el primer paso para llegar a lecturas más plausibles, eliminando poco a poco las lecturas que -examinadas por el grupo- se alejan abiertamente del texto. En un ambiente académico, el estudiar un texto significa consultar las lecturas diferentes a través de la historia para obtener la información

29 Robert Escarpit, Escritura y comunicación, Madrid, 1975, p. 82.

30 Roland Barthes, "Critique à picd d'ocuvre", en: Le Figaro Littéraire, Paris, 15 marzo, 1970, p. 21 (cita no literal en traducción mía). 
más amplia posible sobre su recepción; "Hemos de ver la obra a través de todos los públicos que la han leído". 31 Este proceso de examinación puede llevar a un consenso más o menos amplio, pero nunca total, sobre el sentido. Hay que dejar abiertos para la interpretación, los vacíos donde el texto realmente queda indefinido. Invitan a la "creación traidora" esencial para toda recepción literaria.

Para la explotación didáctica del texto podemos proponer por lo menos tres etapas: 32

a) La proyección subjetiva como etapa necesaria e inevitable de la recepción. En vez de suprimir esta etapa hay que reforzarla a lo máximo para estimular la creatividad. Lecr significa aprender a expresarse.

b) Hacer ver la discrepancia entre la concreción individual y la intención del autor, tomando en cuenta el lugar histórico-cultural de cada uno. Crear conciencia en los estudiantes de los procesos de recepción, y a través de una etapa de relativismo, tratar de objetivar los resultados.

c) Reflexionar sobre si el texto, visto desde su contexto histórico y social, puede ofrecer alternativas de pensamiento y de comportamiento para la praxis vital del lector actual, a pesar de posibles diferencias de situación histónica, estructuras socioculturales, lenguaje.

El provecho pedagógico de tales procedimientos también es subrayado por Jean Verrier:

Cette lecture, bilan de remarques faites en classe au cours de plusieurs lectures différentes, n'est qu'un résultat, parmi d'autres possibles, d'une approche du texte. C'est cette approche dont je voulais avant tout souligner l'intérêt pédagogique. Approche du

31 Doucy, Sanguineti, Barthes, Koehler, ct al., Literatura y Sociedad. Problemas de metodologia en sociología de la literatura, Barcelona (Martínez Roca),
1971 , p. 71.

32 Sigo aquí las propuestas de Heinz IHilmann, en: H. Heuermann, 'tet al., 1975 , op. cit., p. 127. 
texte et démarche pédagogique sont étroitement imbriquées: plus les lectures des élèves seront différentes et plus riche scra le travail d'apprentissage sur les structures narratives; autrement dit, plus on s'écartera d'un supposé modèle et plus l'exercice sera in. téressant pour chacun et pour tous. C'esț la lecture de chaque élève qui est valorisée, non celle du maître, ni celle d l'auteur, ni celle de la majorité du groupe. Par définition, cet exercice est un exercice de groupe; mais le rôle du groupe n'est pas normalisateur, il est révélateur: pédagogie "centrifuge". 3 s

3. En este sentido, también para Jauss resulta muy fructífera la discusión acerca de las preguntas que suscita el texto. 34 (La mayoría de las preguntas han sido formuladas también por los estudiantes mexicanos, implícita o explícitamente):

- Esta historia del Sr. Keuner, ¿es una anécdota o un chiste?

- Su laconismo, ¿es serio o alegre?

- ¿Qué significa que una persona es anónirna y la otra tiene nombre?

- ¿Por qué el Sr. K. reacciona de esa manera incsperada?

- ¿Qué pasa con el opener tan conocido del habla de todos los días, " iNo ha cambiado usted nada!"?

- ¿La reacción del Sr. K. podría ser también la mía? ¿Por qué sí, por qué no?

Lo importante es no pretender llegar a la única respuesta posible, a la "lectura correcta", que'no existe,

Porque el texto de Brecht, como la mayoria de los textos, admite varias interpretaciones: Esta pluralidad de posibles explicaciones es lo esencial del carácter estético del texto y ofrece al análisis. recepcional la oportunidad especial de captar $\rightarrow$ o hasta cambiarel horizonte de expectativas (o, para los marxistas: la ideología) de diferentes capas de lectores. 35

33 Jean Verrier, "La ficclle", en: Poétique, núm. 30, 1970, p. 208.

${ }^{34}$ H: R. Jauss, en: Poetica, 1975, op. cit., pp. 333.334.

a5 H. R. Jauss, Mid:, P. 334 . 


\section{SUBJETIVIDAD Y OBJETIVIDAD EN EL ACTO DE LA LECTURA}

Para profundizar algo más en el problema de la supuesta o real subjetividad de la recepción, trataré de analizar algunos aspectos del proceso de recepción entre el texto y el sujeto o lector. Esta interrelación no es la única en que se concentran las investigaciones "recepcionistas". Para aclarar la relación de los diferentes campos de investigación entre sí, nos puede ayudar el esquema que presentó Lucien Dällenbach en el ya mencionado número de Poétique

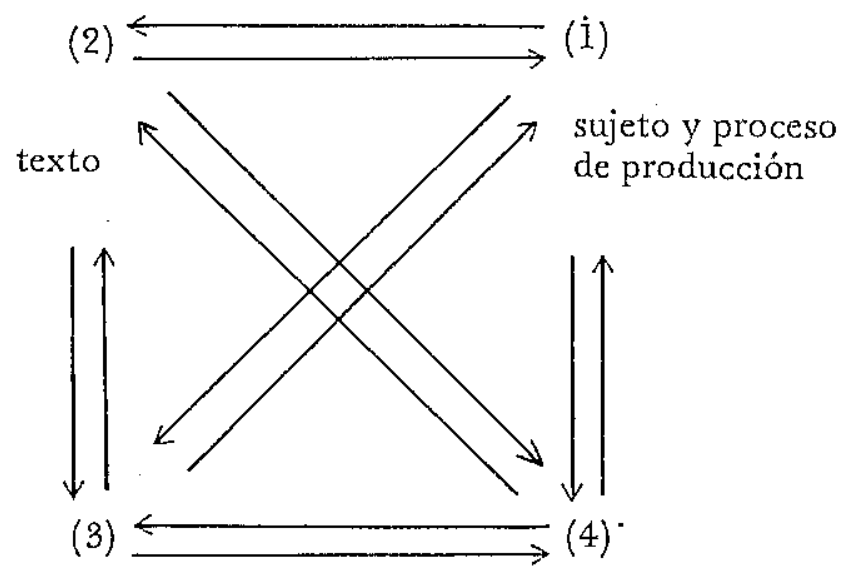

sujeto y proceso

de recepción

contexto histórico inconsciente

En la teoría de la recepción, la relación comunicativa entre texto y sujeto ocupa el centro de interés, aunque la tarea principal reside en la aclaración de todas las diferentes instancias respecto a (3). Recientemente hay una tendencia de aclasar las relaciones entre (3) y (4) y entre (4) y (3), es decir, analizar el aspecto social de la recepción así como el status del lector como sujeto desde un punto de vista ideológico y psicoanalítico.

Me concentraré hoy en la relación (2) - (3), (3) - (2), y me baso para mis explicaciones en los trabajos de Wolfgang Iser. 
Sus investigaciones giran alrededor de la recepción individual de textos literarios, inspirándose para cllo en la fenomenología husserliana y en las reflexiones de Roman Ingarden sobre la concreción y la reconstrucción de la obra literaria. ${ }^{36}$

Los trabajos de Wolfgang Iser nos llevan al centro mismo de nuestra problemática. Su último libro, El acto de lectura. Teoria del efecto estético, ${ }^{37}$ es un estudio lúcido sobre la lectura como operación. Este libro complementa sus investigaciones acerca de las formas comunicativas de la novela que están publicadas bajo el título de Der implizite Leser (1972). ${ }^{38}$

Iser había expuesto lo esencial de su concepto ya en un trabajo anterior en el cual investiga la estructura apelativa de los textos y la ambigüedad como condición del efecto de la prosa literaria. 39

Iser adopta el término de Unbestimmtheit, es decir ambigüedad o indeterminación, siguiendo la terminología de Roman Ingarden, y la define como elemento constitutivo de comunicación entre el texto y el lector. Las Leerstellen, o vacíos que existen en un texto permiten al lector relacionar la experiencia ajena del. texto con sus propias experiencias vitales. Iser nos ofrece todo un catálogo de condiciones formales que generan "vacíos" en el texto. Se puede tratar de técnicas de estructuración como cortes, segmentación, montaje; pueden ser comentarios del propio narrador que descomponen la historia narrada, que le abren al lector un espectro amplio de valoraciones posibles. También la técnica puede consistir en descripciones superprecisas que generan en el lector la necesidad de mayor concentración, de selección,

36 Roman Ingarden, "Konkretisation und Rekonstruktion", en: Rainer Warning (ed.), Rezeptionsästhetik. Theorie und Praxis, Munich (Fink) 1975, pp. \$2-70.

37 Wolfgang Iser, Der Akt des Lesens. Theorie ästhetischer Wirkung, Munich (Fink), 1976.

38 Wolfgang Iser, Der implizite Leser. Kommunilationsformen des Romans. von Bunvan bis Beckett, Munich (Fink), 1972.

39 En lo que sigue me baso en el trabajo de Rainer Warning, "Reseptionsästhetik als literaturwissenschaftliche Pragmatik", en R. Warning (ed.), 1975, op. cit,, pp. 9.41. 
de simplificación. $Y$ finalmente existe toda una serie de técnicas de distanciamiento. Siguiendo la terminología de Waync C. Booth, 40 Iser distingue en la aplicación de estas técnicas entre el reliable narrator o el narrador confiable, y el unreliable narrator o narrador no confiable. El narrador no confiable aparece sobre todo a partir del siglo XIX, y su inconfiabilidad consiste en la intención de emplear estrategias que manipulan al lector a través del texto.

Los "vacios", estos momentos de indeterminación o ambigüedad, solamente pucden provocar el efecto apelativo cuando mantienen una relación con las experiencias que le son familiares al lector. Sin una relación equilibrada entre ambigüedad comunicativa y precisión comunicativa, no se pone en marcha una interacción entre texto y lector. Por consecuencia, Iser enticnde el acto de lectura como un conflicto permanente de dos tendencias: la necesidad de ilusión e identificación del lector por un lado, y la ironía del texto que pone en tela de juicio, en cada momento, sus ofertas de precisión. Toda manifestación de ilusiones es una consecuencia de las decisiones de selección (consciente o inconsciente) por parte del lector. Lo que el lector excluyc queda sin embargo presente como factor potencial de distracción, y la consistencia del nuevo texto del lector nunca será permanente. Así se puede explicar el por qué un texto lleva, sincrónicamente, a concreciones diferentes, dependientes de la selección del lector individual en un contexto social. Y el por qué el texto se realiza, diacrónicamente, de maneras cada vez diferentes, tanto en el plano individual como social.

La pregunta "¿Quién entiende cómo y por qué?" puedc ser intercsante tanto sociológica como psicológicamente. Para el historiador literario adquiere importancia con miras hacia un modelo del texto que da informaciones sobre la "lectura correcta". Por eso se explica el interés de la cstética de la recepción por el lector implícito, por el lector postulado por el texto. Leer "correctamente" no significa, pucs, leer de manera unívoca; significa tratar de dar al texto una interpre-

40 Wolfgang Iser, "Die Appellstruktur der Texte", en R. Warning (ed.), 1975, op. cit., p. 252 . 
tación terminante dónde es unívoco, pero también, mantenerlo abierto dónde se opone a interpretaciones unívocas y, por ende, tiene su carácter provocativo.

Si seguimos las ideas de Wolfgang Iser, una teoría del texto literario -y por consecuencia una didáctica de la literaturano puede existir ya sin incluir al lector. Pero el problema sigue siendo qué clase de lector se está presuponiendo. Porque también el lector implícito no es una abstracción de un lector real, sino sólo un elemento constitutivo del texto para generar, por medio de los "vacíos" estructurales, una tensión productiva en el lector real, o mejor dicho en los múltiples lectores reales.

Una de las críticas que se han formulado frente a las reflexiones sobre una poética de la recepción se dirigía contra la abstracción de un lector ideal sin definir cada vez su situación histórica, social, cultural y psicológica. Así es fácil crear a un lector abstracto, culto, privilegiado. También se ha reprochado al recepcionismo que subestimara el carácter intencional de la producción, que no es el lector el que produce el texto sino el autor, y que este último no ha dejado una libertad total al texto. Otros críticos, como René Wellek en el Congreso de Innsbruck, se sorprendieron ante el "relativismo extremo", ante la "falta de evaluación" de las obras literarias con métodos de la crítica literaria, y ante el predominio de enfoques descriptivos e históricos.

Desgraciadamente aquí no se pueden abarcar todos estos temas, por falta de tiempo. Me limitaré a retomar el problema de la subjetividad que fue objeto de algunas críticas en los últimos años. Parte de la crítica, tanto proveniente desde los insiders como desde fuera, subraya el peligro de un relativismo sin salida, de un pluralismo de opiniones; la teoría de la recepción debería evitar separar la cuestión de la relación comunicativa entre texto y lector, de la pregunta sobre el conocimiento, los valores, la verdad. ${ }^{41}$

Una polémica bastante útil se generó con representantes de la ciencia literaria marxista en la RDA donde desde hace

41 En cste sentido podría entenderse la posición de J. Habermas, como la presentan H. Eggert, H. Ch. Bcrg. M. Rutschky, Die im Text versteckten Schüler' cn: G. Grimm (ed.), Literatur und Leser, 1975. Op. cit., pp. 279 y 417. 
años se está investigando sobre cuestiones de recepción. En la publicación titulada Sociedad-literatura-lectura: Recepción literaria bajo el punto de vista teórico, 42 un grupo de investigadores dirigido por Manfred Naumann dio a conocer su posición frente al problema de la recepción. Se apunta la importancia del "sujeto activo" para la realización de las obras literarias, la "interiorización" paulatina de las experiencias literarias y su efecto retroactivo sobre las lecturas subsecuentes. Pero se previene contra una poética que toma la recepción individual como punto de partida para llegar a regularidades más generales. También la recepción individual, a pesar de ser subjetiva, sólo es una abstracción de muchos componentes de recepción literaria de la sociedad y necesita análisis mucho más amplios antes de llegar a conclusiones.

Concretamente, Naumann critica en el enfoque de Iser su "concepto subjetivado de la obra literaria", 43 que sí puede acarrear experiencias útiles del lector con las obras literarias. Pero, siempre según Naumann, esta experiencia no tiene consecuencias prácticas para "la relación dialćctica entre obra y lector", "porquc la seudoactualización del texto por parte del lector toma como punto de partida una obra aislada de su contexto histórico. Así la recepción permanece arbitraria y sin referencia a valores que podrían lievar más allá de la experiencia individual". 44 Naumann postula por consecuencia una estética de la recepción actual y pasada aplicando el criterio de la función social de la literatura, sin lo cual "no se puede evitar el subjetivismo en la cuestión de los valores". 45

Estas polémicas no quedaron sin respucsta - como era de esperarse- y las discusiones sobre "la parcialidad del método estético-recepcional" 46 condujeron a una aproximación de los puntos de vista. Tras las discusiones necesarias, sigue

42 Manfred Naumann, et al., Gesellschaft - Literatur - Lesen. Literaturrezeption in theoretischer Sicht, Berlín (Aufbau), 1976.

43 Ibid. p. 125 (las traducciones son mias).

44 Ibid., p. 127.

45 Ibid., p. 138.

46 Hans Robert Jauss, "Die Partialität der rezeptionsästhetischen Methode". Epúlogo de H. R. Jauss, "Racines und Goethes Iphigenie", en R. Warning (ed), 1975, op. cit., pp. 352-400. 
vigente la pregunta de si la teoría de la recepción está contribuyendo a la génesis de un nuevo paradigma de la historia literaria. 47

Sea como fuere, me parece muy digno de reflexión lo que escribió Gumbrecht en el prefacio del libro La actual ciencia literaria alemana, que gira ạlrededor de la estética de la recepción:

Lo que aparenta una capitułación ante el subjetivismo resulta scr una vuelta a métodos cientificos. Aceptar la subjetividad es transformarla de critcrio en objeto. 48

Desde entonces, una de las exigencias dirigidas hacia la teoría de la recepción es justamente producir una historia literaria que esté enfocada hacia el citado "objeto". Es decir que -si dejamos a un lado los estudios sobre la recepción de una que otra obra o sobre autores aislados- no existe hasta hoy en día ningún intento convincente de escribir una historia literaria orientada hacia los receptores, y escrita desde la perspectiva de los receptores. ${ }^{49}$ Aúm queda mucho qué hacer en la práctica, como también lo reconoció Jauss en Innsbruck cuando dijo: "Ya sonó la hora de la aplicación."

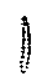

DIETRIGH RALL

Facultad de Filosofía y Letras, UNAM

47 Sobre este problema consúltese la bibliografia mencionada en la nota 11.

48 H. U. Gumbrecht, "La situación de la 'Litcraturvissenschaft" alcmana: Análisis y persepctivas", en: La actual ciencia literaria alemana, op. cit. p. 32.

49 Como los comprucba, por ejemplo, G. Grimm en Rezeptionsgeschiehte, op. cit., p. 144 . 